\title{
El compromiso social en los Principios de economía política y en la Sujeción de las mujeres de John Stuart Mill (con las contribuciones de Harriet Taylor Mill)
}

\author{
Social Compromise in Two Books by John Stuart Mill: Principles of \\ Political Economy and The Subjection of Women \\ (With Harriet Taylor Mill's Contributions)
}

\author{
ELENA GALLEGO ABAROA \\ Universidad Complutense de Madrid
}

\begin{abstract}
RESUMEN
En este artículo se han revisado los contenidos de tres obras: Principios de economía política (1848) y La sujeción de las mujeres (1869) de John Stuart Mill y "La liberación de las mujeres" (1851) de Harriet Taylor. La interpretación de los textos se ha realizado bajo la consideración de que existía un ideario compartido y un compromiso social explícito en los dos autores, inspirado en sus deseos de proyectar una sociedad mejorable que implicaba directamente a los colectivos de las mujeres y de los trabajadores. Las ideas que se exponen se han distribuido en cinco planos: el freno de la tradición y de la costumbre al progreso social, la educación como elemento básico para la evolución personal, el derecho a ejercer el sufragio y a ser elegido, el acceso al mercado de trabajo y el futuro progreso de los trabajadores.
\end{abstract}

PALABRAS CLAVE: Economía Politica, Redistribución de rentas, Sufragio Femenino, la Mujer en el mercado de trabajo, Trabajadores

Códigos JEL: B12, B20, B31, B54

\section{ABSTRACT}

This paper consists of a re-reading of three works by John Stuart Mill and Harriet Taylor: the Principles of Political Economy (1848), The Subjection of Women (1869) both by J.S. Mill and Harriet Taylor's essay, "The Emancipation of Women" (1851). The paper seeks to reinterpret these texts, seeing them as part of a joint pool of ideas and an explicit social and political programme set out by the two authors, a programme inspired by their wish to improve the lot in society, above all, of women and of the working classes. The ideas which underlie this programme have been classified under five headings: tradition and custom as stumbling blocks to social progress; education as a fundamental element in personal development; the right to vote and to be elected; freedom of access to the labour market; and finally the future advancement in the condition of the working classes

KEY WORDS: Political Economy, Income Distributions, Women's Suffrage, Women And

The Labour Market, Working Classes

JEL Codes: B12, B20, B31, B54 


\section{Introducción ${ }^{1}$}

$\mathrm{J}$

ohn Stuart Mill (1806-1873) fue un prolífico escritor que se ocupó de materias tan diversas como la economía, la ética, la lógica, la filosofía de la historia, la política, la educación y la igualdad de las personas. Si en general se le puede considerar un perseverante erudito, en el caso de la ciencia social ha representado un referente histórico para analizar los cambios económicos y sociales ocurridos durante el siglo XIX en la cultura occidental. El propósito de este trabajo es escoger una parte de su pensamiento, el que estaba conectado a los asuntos que trataban sobre la situación económica y social de las mujeres y de los trabajadores, con el objetivo de relacionar las opiniones vertidas en dos de sus publicaciones más reputadas: los Principios de economía política (con algunas de sus aplicaciones a la filosofía social) y La sujeción de las mujeres. Poner en relación los contenidos de los dos libros citados, el primero publicado originalmente en 1848 y el segundo en 1869, permite dilucidar el compromiso de Mill en proyectar un camino que permitiera avanzar, a todos los ciudadanos, hacia una sociedad más abierta, más libre y próspera que la suya. En este trabajo se destaca el alcance que tuvo Harriet Taylor (1807-1858) en la inspiración de su ideario y en la colaboración directa en algunos capítulos de los dos libros considerados; la influencia que ejerció Taylor en Mill tuvo una especial relevancia en las cuestiones referentes a la defensa de los derechos de las mujeres y a determinadas disquisiciones sobre el progreso de los trabajadores. El conocimiento de su relación y la influencia mutua que nació de ella son conocidos gracias al testimonio que dejó Mill en su Autobiografía ${ }^{2}$.

[Fecha de recepción del original, 26 de junio de 2009. Versión definitiva, 12 de marzo de 2010]

1 Quiero agradecer a los profesores José Antonio Sebastián Amarilla y John Reeder la lectura previa que han hecho de este artículo así como las correcciones realizadas del mismo; sus comentarios y sus consejos han mejorado, sin duda, el contenido del trabajo. Igualmente, quiero hacer extensivo el agradecimiento al Consejo editorial de IHE y a los dos evaluadores de este trabajo por sus observaciones, indicaciones y sugerencias que han enriquecido la investigación.

2 Este trabajo toma como base bibliográfica principal sobre la colaboración intelectual entre Harriet Taylor y John S. Mill a las obras de Alice. B. Rossi (1970) y de Friedrich A. Hayek (1951) porque sus publicaciones respectivas representan una referencia esencial sobre la discusión de su mutua influencia intelectual, abriendo el debate de todos los estudios posteriores. Además, son relevantes dichas investigaciones, en este trabajo, porque revisaron documentalmente el dilema de la colaboración de Taylor sobre los Principios de economía política y sobre la Sujeción de las mujeres de Mill, e hicieron anotaciones sobre cuestiones de contenido económico que interesa destacar en este artículo y que no se encuentran en otras fuentes. En sus correspondientes estudios (Rossi-Hayek) fueron rigurosos y comedidos en el alcance de sus indagaciones, dado que, en realidad, Harriet Taylor Mill no aparecía formalmente como coautora de las obras firmadas únicamente por John Stuart Mill. No obstante, hay que detallar que hay abundante documentación bibliográfica más actualizada y generalista sobre la relación intelectual de Taylor-Mill, y que conviene reseñar. Desde una interpretación feminista son señalados los trabajos de Evelyn Forget (2003), Julia Annas (1998) y Michèl Pujol (1996). Jo Ellen Jacobs es una distinguida estudiosa de las obras de Harriet Taylor Mill, y tiene publicado en el año 1998, junto con Paula Harms Pyne, un compendio de sus obras, titulado The Complet Works of Harriet Taylor Mill, donde se incluyen trabajos literarios que no estaban recogidos inicial- 
El legado de John S. Mill no se puede comparar en extensión y en profundidad con los manuscritos que ha dejado Harriet Taylor. No obstante, no ha cesado el interés académico de rescatar algunos escritos poco conocidos de Taylor que pueden ensanchar la sombra de su legado ${ }^{3}$. En el deseo de remover los convencionalismos y prejuicios de la sociedad de su época, Mill y Taylor rompieron con las tradiciones de unas relaciones sociales y laborales obsoletas. John Stuart Mill y Harriet Taylor representaron, tanto por su forma de vida como por sus opiniones y su obra escrita, a una parte de la vanguardia intelectual de la sociedad británica del siglo XIX. Su atención a los derechos políticos y civiles de las personas, sin diferenciar a unas de otras por su condición sexual, de raza o clase, y sus argumentaciones, siempre encaminadas hacia la consecución de una sociedad más justa y feliz, les llevaron al análisis de las cuestiones referentes a la situación política, social y laboral de los más débiles, ocupando las mismas una parte significativa de sus reflexiones. La siembra de su pensamiento compartido, en lo que se refiere a las cuestiones de igualdad sexual, tuvo continuidad en los escritos de Helen Taylor ${ }^{4}$.

Taylor y Mill fueron conscientes de que el sometimiento de las mujeres estaba firmemente enraizado en su dependencia económica y, si se les abrían las vías de acceso a la educación y a los empleos profesionales, se estaría rompiendo la sujeción mercantil y afectiva que las apartaba de su propia evolución personal. Esa es la ra-

mente en la obra referenciada de Hayek, y en donde se destacan aspectos de la biografía de Harriet Taylor que no se encuentran en otros trabajos sobre su vida. Andrew Pyle, en 1995, realizó un estudio muy sugerente del impacto social de la Sujección de las mujeres en el año de su publicación. Ann P. Robson y John B. Robson (eds.) compendiaron en el año 1994 los trabajos de Mill, Taylor y Taylor, con la novedad de considerar la continuación de las disquisiciones sobre la igualdad sexual en los escritos de Helen Taylor, la hija de Harriet Taylor. Gail Tulloch publicó en 1989 un libro donde se trataba de integrar la Sujeción de las mujeres en el contexto filosófico de la obra de Mill. También es reseñable el estudio introductorio de Ann P. Robson sobre los escritos de corte periodístico de Mill publicado en 1986, así como el trabajo de Stefan Collini y de John M. Robson que sirvió de presentación introductoria al volumen dedicado a los Ensayos sobre la igualdad sexual, leyes y educación de 1984. Phyllis Rose publicó en 1983 un artículo sobre la influencia emocional de Taylor sobre Mill. Igualmente, el conocimiento de una parte de sus conversaciones personales se enriquece con la recopilación epistolar de Francis Mineka y Lyndley Dwigth del año 1973. Las investigaciones de Kizner, Robson y Robson, Collini y Robson y Mineka y Dwight, están incluidas en las obras completas de John S. Mill editadas por la universidad de Toronto. También hay que señalar la fuente documental incluida en la biografía que escribió Michael S. J. Packe en 1954. Evelyn L. Pugh publicó en 1978 un artículo sobre el impacto de las propuestas de Mill y Taylor en los Estados Unidos. En lo referente a España, en el año 2000 se publicó la traducción del libro citado de Alice B. Rossi, prologado por Victoria Camps y con un apéndice de Emilia Pardo Bazán dedicado a comentar la Sujeción de las mujeres (que tradujo literalmente como "la esclavitud femenina"). Elena Gallego Abaroa tiene dos trabajos sobre Harriet Taylor Mill. En el año 2004 presentaba, en el libro Mujeres economistas 1816-1898, una reflexión económica de la "Liberación de las mujeres" de Harriet Taylor, en la que se planteaba su posible colaboración en el Libro IV de los Principios de economía política de John S. Mill; y en el año 2007 analizaba la biografía de Taylor imbricándola a sus opiniones más innovadoras en el contexto temporal la sociedad británica del XIX.

Jacobs (1994), p. 159.

Robson y Robson (1994), p. 26. 
zón principal de que el objetivo de este trabajo se centre en la interpretación de las exposiciones de contenido económico que desplegaron, todas ellas encaminadas a contrarrestar los argumentos de los detractores de la emancipación de las mujeres. Cuando se refirieron al futuro de los trabajadores, en el capítulo VII del libro IV de los Principios, apuntaron hacia unas nuevas relaciones de producción. Señalaron la importancia que estaba tomando la concienciación de los intereses laborales por parte de los trabajadores, no siempre en consonancia con los de sus patronos; y destacaron la virtud de la educación y de la instrucción de los obreros. En este artículo se señala la importancia que tuvo Taylor en la comprensión de una parte de la obra de Mill 5 .

Entre las obras principales que se han manejado para desarrollar las ideas que van a exponerse a continuación, tres de ellas estaban firmadas por John S. Mill: Principios de economía, La sujeción de las mujeres y la Autobiografía. Harriet Taylor dejó muy poca obra escrita, pero por suerte, se cuenta con el artículo que publicó en 1851 en la Westminster Review, titulado "La liberación de las mujeres", al que hay que añadir el reconocimiento público que se hizo de su contribución al libro IV de los Principios de economía.

\section{Por qué le interesaron a John Stuart Mill las cuestiones referentes a la desigualdad social}

Puede considerarse que existe un principio unificador de la obra de Mill en cuanto a su visión de una sociedad futura mejorable, construida sobre una filosofía social individualista basada en la responsabilidad ${ }^{6}$. Este principio está en la base de los argumentos expuestos en el capítulo de los Principios dedicado al futuro de la clase trabajadora y en los planteamientos de La sujeción de las mujeres, a saber: rechazo de la lucha de clases y del sometimiento sobre las mujeres, repugnancia frente a la esclavitud, extensión del sufragio a las mujeres y a la clase trabajadora, y una organización económica que concebía beneficiosa para los trabajadores la aplicación del sistema cooperativo en la producción.

Las ambiciones intelectuales de Mill, como erudito preocupado en crear opinión, le llevaron a interesarse reiteradamente por la moral social. Con el objetivo de activar las conciencias y desactivar los prejuicios de la clase dirigente, buscaba favorecer un proceso renovador de la sociedad de su época. Fue a partir de 1859, después de morir Harriet Taylor, cuando sus artículos, sus libros y, en general todas sus publicaciones, llegaron a un amplio espectro de lectores, y Mill era consciente de

Rossi (1970), p. 24.

Schwartz (1968), p. 327. 
ello, como puede comprobarse leyendo su Autobiografía o parte de su correspondencia $^{7}$. Como ha quedado reflejado en el obituario de Mill que firmó John Morley, sus opiniones eran reverenciadas como las de un oráculo, tanto dentro como fuera de las fronteras británicas ${ }^{8}$. Lógicamente, el mismo interés que le impulsaba a conseguir resonancia y difusión de sus convicciones entre sus conciudadanos le hacía seleccionar cuidadosamente el mejor vehículo de la transmisión de sus ideas, eligiendo el tipo de publicación más adecuado a sus objetivos. Igualmente, fue muy cuidadoso en la elección del momento más oportuno para la aparición de sus escritos, a fin de facilitar la recepción de los mismos por la sociedad británica del XIX ${ }^{9}$.

Dado que Mill, en su madurez, fue un escritor de una popularidad extraordinaria entre sus contemporáneos, y que sus publicaciones eran textos manejados en las universidades británicas, analizados y estudiados por la academia, era importante que sus libros se vendieran también entre el público no especializado, de otra manera sus ideas nunca habrían tenido la fuerza que demostraron en años posteriores. Contaba Mill en su Autobiografía que, con sacrificio de sus intereses pecuniarios, había decidido renunciar al beneficio derivado de las ventas de los libros de las ediciones baratas, para facilitar el acceso de su obra a las clases trabajadoras con el objetivo de formarles en el conocimiento de la estructura económica, social y política de Gran Bretaña. Y así hizo con tres de sus textos: Principios de economía política, Sobre la libertad y Consideraciones sobre el gobierno representativo ${ }^{10}$. Esta notoriedad como persona reputada e influyente iba a ser determinante en la elección de las cuestiones que deseaba verter entre sus coetáneos, siendo consciente de su posición ventajosa de comunicador.

Los Principios de economía política, que es uno de los libros que sirven de eje para este trabajo, se editaron, en vida del autor, en siete ocasiones. La primera edición de 1848 ya recogía la separación entre las leyes de la producción y de la distribución, así como el capítulo referente al "futuro de la clase trabajadora", que en este artículo cobran especial relevancia. La segunda edición de 1849 ampliaba el capítulo en el que se ordenaban algunas matizaciones que evitaban la reprobación maximalista del socialismo, un debate que se estaba planteando en su época desde los extremos y que no era la posición de Mill. La tercera edición de 1852 sí introdujo más variaciones, reescribiéndose de nuevo varios capítulos del libro, entre ellos el capítulo sobre la propiedad y el capítulo referido "al porvenir de la clase trabajadora”, que incluyó como novedad algunos ejemplos de la experiencia de las asociaciones cooperativas que se habían constituido con éxito en Francia, y la compatibilidad, en opinión de

\footnotetext{
Carta a Charles A. Cummings (23 de febrero de 1862) y carta a Helen Taylor (7 de febrero de 1860), en Mineka y Lindley (1972), p. 673.

Morley (1873), p. 670.

Collini, en Robson (1984), p. XI.

Mill (1986), p. 260.
} 
Mill, entre la tendencia a la trasformación social, que favorecía dichas asociaciones, y la competencia, bienhechora siempre de los ajustes mercantiles. En la cuarta edición de 1857, revisada completamente, se añadieron algunas explicaciones sobre la influencia del crédito en los precios y la regulación del papel moneda convertible. La quinta edición de 1862 había actualizado los hechos que servían como ejemplos en los razonamientos del libro. La sexta edición de 1865 se hizo en dos versiones. La primera fue, como otras revisiones anteriores, retocada levemente en general, y sólo incluía variaciones reseñables en el capítulo dedicado a la tasa de interés, con unas observaciones sugeridas por John Elliot Cairnes. La segunda versión fue una "edición popular" y barata, en la que se tradujeron al inglés todas las frases originalmente expresadas en otros idiomas, y se redujeron el número y la extensión de las citas. Por último, la séptima edición de 1871, era una revisión con algunas correcciones verbales de la publicación anterior.

La puesta en sociedad de La sujeción de las mujeres aconteció en 1869. La obra reflejaba, en palabras de Mill, "el caudal de pensamiento hecho en común junto a Harriet Taylor". Si bien había comenzado la redacción del libro entre 1860 y 1861, dejó reposar varios años el manuscrito con el fin de mejorarlo paulatinamente, y decidir "publicarlo cuando su acogida pareciese más útil", determinación que tomó dos años después de haber solicitado en el Parlamento el voto para las mujeres. El momento de la aparición de esta obra fue el elegido para remover un caudal de poderosas aguas subterráneas de la sociedad británica: la costumbre que aceptaba la idea de la servidumbre de una parte de la humanidad sobre la otra, justificada ancestralmente por la debilidad física de las mujeres. Pero el problema verdaderamente subyacente que había que afrontar, en su opinión, era más profundo: la aceptación consuetudinaria del derecho del más fuerte en el diseño de la organización social y productiva.

Para determinar si las opiniones de Mill eran o no excepcionales en su contexto histórico, puede resultar esclarecedor observar el eco social de La sujeción de las mujeres, que fue inmediato, como se puede demostrar contrastando los numerosos comentarios surgidos en los medios de comunicación de la sociedad británica del XIX con tal evento. No obstante, se descubría a un John Stuart Mill predicando en solitario. En 1869, año de la edición del libro, emergía la obra reseñada en seis revistas informativas: The Saturday Review, The Athenaeum, The Theological Review, The Christian Observer, Blackwood's Magazine y The Edinburgh Review. En el año 1870 fue comentada en otras cuantas: The Westminster Review, Fraser's Magazine, The Contemporary Review y en The Fornightly Review en dos ocasiones; la primera firmada por Millicent Garrett Fawcett y la segunda por John Morley. Incluso, unos años después, en 1874, continuaba el debate sobre el libro en la Macmillans Magazine, y se responsabilizaban de los artículos Goldwin Smith y J.E. Cairnes respectivamente, en este caso al hilo de la controversia sobre el sufragio universal. Las dos primeras edicio- 
nes de La sujeción de las mujeres se habían agotado rápidamente, y fue traducido al alemán, al francés y al polaco ${ }^{11}$.

Las apostillas más críticas aparecieron en The Saturday Review (junio de 1869, anónimo), en la que se mostraba a un Mill equivocado en sus argumentaciones e irreconocible si le comparaba con la autoría de sus otras obras. En The Christian Observer (agosto de 1869, anónimo), también se revelaban en total desacuerdo con Mill, cuyas subversivas propuestas entorpecían las relaciones humanas. Algo parecido se repetía en la Blackwood's Magazin (septiembre, 1869, Anne Mozley), donde se presentaba a Mill como el único defensor masculino de un pensamiento irreverente y disconforme con el resto del mundo. Henry Taylor en la Fraser,s Magazine reconocía grandes méritos a la figura de Mill, pero también se enzarzaba en las complicaciones legales de sus novedosas propuestas, que de llevarse a cabo, dificultarían en exceso el ordenamiento legal de la sociedad británica. Los comentarios más favorables provenían de The Fornightly Review, de la mano de Millicent Garrett Fawcett, que amparaba las propuestas millianas, a la vez que se mostraba sorprendida de la general falta de apoyo masculina en el debate sobre el sufragio universal. No obstante, se congratulaba del compromiso favorable que mostraban unos pocos, aunque muy sobresalientes líderes políticos y pensadores, como Gladstone, Disraeli, Brigth, Mill y lord Salisbury ${ }^{12}$. Goldwin Smith también se había posicionado en desacuerdo con Mill en la Macmillans Magazine, considerando que no era necesario ampliar el sufragio a las mujeres porque la mayoría de ellas se sentían representadas e identificadas en los intereses de sus maridos. Este artículo fue respondido en la misma revista por J. E. Cairnes, que contraponía los argumentos de Mill y los de Smith, y se decantaba favorable al sufragio universal y a la incorporación al mercado de trabajo de las mujeres en competencia profesional con los varones.

\section{Las ideas compartidas en las obras de Harriet Taylor y John S. Mill}

La cuestión importante que hay que reseñar es por qué Mill escribió una parte de estas obras seleccionadas junto a Harriet Taylor, como ha quedado reflejado en la Autobiografía de Mill y, sin embargo, ella no apareció nunca como coautora de las mismas. Hay dos justificaciones razonablemente convincentes para explicarlo. En primer lugar, pudo deberse a la incomodidad de John Taylor, el primer marido de Harriet Taylor, en desacuerdo completo con las muestras de amistad que Mill y Taylor paseaban públicamente por Londres desde 1831. Para apoyar esta primera

$11 \quad$ Packe (1994), p. 496.

$12 \quad$ Pyle (1995), pp. 224, 285 y 303. 
tesis, se cuenta con el libro de Hayek, John Stuart Mill and Harriet Taylor. Their friendship and subsequent marriage, publicado en el año 1951, en el que se recogen muchas de las opiniones de los implicados a través de su propia correspondencia.

Taylor le contaba a su marido en una misiva del mes de febrero de 1848 que se encontraba absorbida completamente en la revisión del manuscrito —refiriéndose a los Principios-, de manera que no podía abandonar la ciudad en esas fechas. Y, un mes antes de que apareciera la primera edición de los Principios de economía política, lo que ocurrió en abril de 1848, Harriet Taylor escribió a su marido otra carta, fechada el 31 de marzo, en la que le contaba que el libro se iba a publicar en los próximos diez días, y le comunicaba su indecisión, aunque sí su deseo, de que el libro estuviera dedicado a ella, y le pedía su consejo sobre la cuestión. La rápida respuesta de John Taylor, fechada el 3 de abril, mostraba explícitamente su extrema incomodidad si tal hecho ocurriera, recordándole que la dedicatoria no haría otra cosa que acrecentar ciertos rumores que ya estaban apaciguados, y le exhortaba a que no la aceptara. Finalmente, sólo aparecieron unos pocos ejemplares, señalados, editados para regalo, en los que aparecían impresas a pie de página las siguientes palabras:

“Para Mrs. John Taylor, la persona más eminentemente cualificada de todas las conocidas por el autor, capaz de originar y de apreciar las especulaciones del avance social, en este intento de explicar y difundir nuevas ideas, muchas de las cuales fueron aprendidas de ella misma, dedicado con el mayor respeto y aprecio"13.

El hecho de que se retirara la dedicatoria de la edición normalizada del libro demuestra que los protagonistas decidieron arropar la decisión de John Taylor, y desvincular a Harriet Taylor de la producción del libro. No parece, por tanto, nada lógico que pudiera recogerse públicamente la autoría de uno de los capítulos del libro citado.

La segunda explicación que justifica por qué ella tampoco aparecía como coautora o inspiradora de La sujeción de las mujeres es que cuando se publicó dicha obra, en 1869, ella ya había fallecido. No por eso no debía aparecer como alentadora y creadora del libro, dado que la tesis que se defiende en este artículo es que Mill recogió una parte extensa del ensayo de Taylor para desarrollarlo. En la Autobiografía contaba Mill cómo había sido su hijastra, Helen Taylor, la que le requirió el esfuerzo de abordar la tarea de escribirlo para dejar constancia de sus opiniones sobre esa gran cuestión. John Stuart Mill contaba que el libro contenía valiosas ideas de su hija, e incluso, algunos fragmentos provenían de sus propios escritos, que en opinión de su autor enriquecían la obra. Y, una vez más, comentaba que los pasajes más 
eficaces y profundos pertenecían a su esposa y provenían del repertorio de sus ideas compartidas, emanadas de sus innumerables conversaciones ${ }^{14}$.

Alexander Bain, amigo personal de John Stuart Mill además de su primer biógrafo, no compartía los elogios intelectuales que Mill había prodigado a Taylor. Bain tuvo acceso a las pruebas de imprenta de la Autobiografía de Mill y escribió a Helen Taylor para intentar suavizar en la publicación final las alabanzas que él consideraba excesivas hacia la figura de Harriet Taylor. Entre otros estudiosos de la obra de Mill, como han sido Keith Rinehart y Jack Stillinger, se puede observar que tampoco fueron partidarios de reconocer las influencias directas del pensamiento de Taylor en la obra económica de Mill ${ }^{15}$.

Se pueden clarificar las ideas compartidas entre ellos repasando los contenidos de las dos obras claves que escribieron en favor del reconocimiento de los derechos de las mujeres, a saber: "La liberación de las mujeres" de Harriet Taylor y La sujeción de las mujeres de John Stuart Mill. Si se efectúa un análisis comparado de los dos ensayos citados, se observa el paralelismo argumental desarrollado en las dos publicaciones ${ }^{16}$.

Puede considerarse, razonablemente, que la obra referida de Mill fue una extensión del manuscrito original de Taylor. El volumen de Mill se editó en 1869 y el ensayo de Taylor se había publicado, primeramente, en 1851. En 1859 apareció un compendio de dos volúmenes que recogía unas cuantas Disertaciones y comentarios de Mill; entre ellos estaba incluido el ensayo de Taylor, en esta ocasión prologado por él ${ }^{17}$. En las palabras introductorias que le dedicaba a su compañera, ya fallecida, se traslucía la admiración que sentía por ella, y se exaltaba la profundidad y la brillantez del pensamiento de Taylor. Advertía Mill en dicho prólogo que el ensayo estaba destinado al lector corriente, porque el interés de su autora había sido dirigirse al mayor número de personas posible, de manera que habría rebajado la altura de sus pensamientos en beneficio de la comprensión de los mismos, orientándose hacia un público heterogéneo, conformista en lo social y poco versado en la discusión crítica. Esta decisión de Taylor habría implicado que en el texto no quedara reflejada toda la agudeza y la inteligencia de su autora, según contaba Mill.

Comparando los textos, es curioso comprobar que en los escritos de ambos autores hay una forma de razonar temporalmente distinta. Harriet Taylor parece hacerlo como si ya estuviera en el tiempo futuro, en el que estarían produciéndose los ajustes correspondientes a la nueva situación en la que se encontraban las mujeres; por su parte, John Stuart Mill se posiciona en su tiempo real y en el marco de su propia sociedad, en el que las mujeres tenían mucho más camino por recorrer.

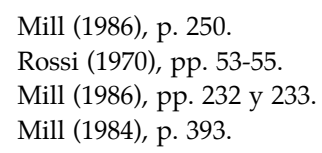




\subsection{El freno a la evolución de las ideas: la tradición y la costumbre}

En opinión de Harriet Taylor, la tradición y la fuerza de la costumbre eran los obstáculos principales para la evolución del progreso social, y así lo relataba en su artículo de 1851. Este escollo, recurrente en la historia, resultaba especialmente funesto en lo relativo a la conquista de los derechos de las mujeres. Era ciertamente incomprensible que los argumentos en contra de la libertad de la mitad de la humanidad se centraran en que las cosas siempre habían sido así. El origen del castigo estaba cimentado sobre la debilidad física de las mujeres, que las había aprisionado en una situación de inferioridad legal efectiva. Suponía Taylor que el prejuicio contra lo nuevo era históricamente uno de los más arraigados en la sociedad, por el simple temor hacia lo desconocido. Puede leerse literalmente que el obstáculo más grave e importante que había que sortear era "el prejuicio de la costumbre, que estaba instalado del lado de la injusticia". Para ella resultaba inadmisible carecer del derecho a tomar sus propias decisiones personales. Dejó escrito que:

“... la esfera propia de todos los seres humanos debe de ser la más amplia y elevada que éstos puedan alcanzar. Y ésta no puede conocerse sin una total libertad de elección" ${ }^{18}$.

No obstante, Taylor era optimista en sus apreciaciones, porque observaba con confianza los cambios que se estaban produciendo en la sociedad del siglo XIX, que mostraban el debilitamiento de los convencionalismos, iniciándose, con esperanza, el camino hacia una sociedad más abierta.

Con este mismo argumento comenzaba Mill las disertaciones de su ensayo. Decía que el término antinatural generalmente solía significar algo desacostumbrado, y que todo lo que es acostumbrado, por el contrario, parecía lo natural. En su opinión, esto es lo que había ocurrido históricamente con las mujeres, cuyo sometimiento “... provenía de la costumbre universal, y cualquier derogación de esta costumbre parece, claro está, antinatural" ${ }^{\prime 19}$.

Abundando en esta misma idea de la inercia conductual consuetudinaria, siempre hostil hacia nuevas sociedades más abiertas y justas en sus derechos, John S. Mill anotaba como contraejemplo la ausencia de prejuicios británicos a tener reinas como cabezas gobernantes, algo que resultaba ciertamente asombroso e imposible de sobrevenir en otras "partes alejadas del mundo".

Ambos pensadores recurrieron a la historia para señalar la capacidad del buen gobierno de algunas mujeres, y demostrar con ello el potencial de las mismas en la más alta gestión de una nación. Por ejemplo, en el manuscrito de Taylor se nombra-

Taylor Mill (1851), pp. 94 y 95.

Mill (1869), p. 158. 
ban a la reina Isabel I de Inglaterra y a la reina Isabel de Castilla. Pero el problema que planteaban sus oponentes era más peliagudo, porque no les bastaba con reconocer las dotes de mando y gobierno de unas cuantas mujeres en el pasado para aceptar la invalidez de sus tesis. El fondo de la cuestión era si la política resultaba adecuada para las mujeres de todo el espectro social ${ }^{20}$.

\subsection{La educación como camino liberador de las mujeres}

El asunto de la educación de las mujeres era vital para Harriet Taylor, destacándolo en su ensayo como una de las principales demandas que había que conquistar en el camino hacia la normalización política, social y económica. El comienzo de su artículo lo dedicaba a reflejar las conclusiones de una convención de mujeres celebrada en 1850 en el estado norteamericano de Ohio. Entre dichas conclusiones se señalaba, en primer lugar, la importancia del acceso a la educación para hacer avanzar la posición de las mujeres en la sociedad. Concretamente se indicaba que:

“... las mujeres deberían de poder acceder a las escuelas primarias y secundarias, universidades e instituciones médicas, legales y teológicas" ${ }^{21}$.

En el ensayo de John S. Mill también emergía la trascendencia de la educación de las mujeres en reiteradas ocasiones. Y no era únicamente una cuestión primordial en opinión del propio autor, sino que la educación estaba siendo clamorosamente reclamada por las propias mujeres británicas del siglo XIX. Así lo dejó reflejado Mill en un párrafo de su obra, en el que había recogido el hecho histórico de la actitud reivindicativa de millares de mujeres, que dirigidas por las más eminentes y conocidas por el público, estaban solicitando insistentemente al Parlamento británico el derecho a recibir una educación que comprendiera las mismas ramas del saber y tuviera la misma solidez que la de los hombres. Apostillaba Mill que dichas peticiones tenían cada vez mayor probabilidad de éxito. Las mujeres británicas eran conscientes de que el derecho a la educación les abría las puertas a otras reivindicaciones igualmente importantes para ellas: la admisión en profesiones y ocupaciones que hasta ahora les estaban vedadas, y el derecho al sufragio femenino ${ }^{22}$. Precisamente, una escritora de textos económicos como fue Millicent Garrett Fawcett, discípula de Mill y comprometida políticamente con el sufragio femenino, era una de estas mujeres, exigentes con el acceso a la educación para avivar el proceso de modernización de la vida de las mujeres británicas.

\footnotetext{
Taylor Mill (1851), pp. 97 y 98.

Taylor Mill (1851), p. 90.

Mill (1869), pp. 159 y 160.
} 
Si reparamos en el lado negativo de la educación secular, que era la historia de un adiestramiento nocivo y contrario al progreso de las mujeres, no les cabían dudas a ninguno de los dos autores que la educación se había utilizado como instrumento de sometimiento. Harriet Taylor criticó la postura de los reformadores moderados de la educación, que, en su opinión eran defensores de una educación aparente, dirigida a ejercitar a las mujeres con el fin de que fueran unas buenas compañeras de sus maridos, buenas escuchantes y comprensivas siempre, capaces de absorber con provecho la sabiduría de sus cónyuges. Continuaba Taylor apuntando que, mientras se les denegara a las mujeres la dignidad del pensamiento en sí mismo, el acceso profesional y la verdadera educación para su propio desarrollo, y no en función del otro sexo, los poderes mentales de las mismas serían un accidente excepcio$\mathrm{nal}^{23}$.

Se pueden encontrar opiniones semejantes en las cavilaciones de John Stuart Mill, que le llevaron a constatar un adoctrinamiento colectivo originado en el poder de los hombres y de terribles consecuencias para las mujeres. En concreto escribió que:

“... los amos de las mujeres quisieron algo más que una simple obediencia y encaminaron toda la fuerza de la educación para conseguir su propósito. Así, todas ellas eran adiestradas desde su niñez en la creencia de que el ideal de su carácter era absolutamente opuesto al del hombre: se las enseñaba a no tener iniciativa y a no conducirse según su voluntad consciente, sino a someterse y a consentir en la voluntad de los demás" ${ }^{24}$.

Este autor profundizaba en este aspecto, y enlazaba las consecuencias de esta mala educación con la atracción natural de los sexos y con la dependencia económica de las mujeres, de manera que quedaban condenadas a que su carácter y su aspecto exterior fuera una parte esencial del atractivo sexual.

\subsection{El derecho a votar y a ser elegido}

El empuje del proceso industrializador del siglo XIX en Gran Bretaña estaba favoreciendo una profunda transformación social y presionando el cambio del sistema representativo en la Cámara de los Comunes. La reforma electoral de 1832, durante el reinado de Guillermo IV, reconoció una nueva estructura de la sociedad británica, y consideró necesario ampliar el sufragio a los distritos urbanos. La reforma defraudó a los políticos radicales, entre los que se encontraba John S. Mill, partidarios de

\footnotetext{
Taylor Mill (1851), p. 108.

Mill (1869), p. 161.
} 
una modificación electoral más profunda donde se reconociera el sufragio universal. No obstante, los cambios tuvieron un alcance democrático mayor del esperado, al reducir el predominio de los terratenientes en la Cámara de los Comunes y transferir una parte del poder político a la creciente clase media urbana. La reforma electoral había alentado el nacimiento del cartismo, un movimiento político obrero de carácter nacional surgido en 1837, que exigía entre sus demandas más significativas el sufragio masculino universal.

La segunda reforma de 1867, ya en la época victoriana, reconoció el derecho a votar a los trabajadores cualificados que detentaban derechos de propiedad, un paso más en el avance de la clase media y de los trabajadores, que con el incremento de sus ganancias estaban ascendiendo en la escala social, mostrándose la fuerza de una conciencia de clase que demandaba una cuota de poder político en detrimento de las viejas oligarquías británicas, ligadas históricamente a la propiedad de la tierra. El crecimiento industrial estaba estimulando el desarrollo democrático ${ }^{25}$.

Asimismo, las reivindicaciones de los derechos políticos, como era el caso de las demandas en favor del sufragio universal, iban acompañadas de otras demandas sociales, como el derecho de huelga o la jornada laboral de diez horas. El sistema político inglés era observado desde el conjunto europeo, en el deseo de imitar la práctica de la alternancia democrática de la formación de los gobiernos ${ }^{26}$.

En este marco en el que pugnaban los nuevos poderes económicos y los antiguos poderes políticos, entraron las mujeres a demandar su cuota de representación institucional y su derecho a ejercer el sufragio y, tanto John S. Mill como Harriet Taylor lo reflejaron en sus publicaciones ${ }^{27}$.

El artículo de Taylor, que como se ha apuntado anteriormente recogía las conclusiones de la convención de mujeres de Ohio de 1850, señalaba que en el contexto histórico norteamericano se estaba produciendo una confluencia de intereses entre las mujeres y los hombres de color, deseosos ambos colectivos de escapar de "la aristocracia del color" y de "la aristocracia del sexo". Dentro de la línea argumental que desarrollaba, Taylor incidía en la importancia de la reivindicación de las mujeres a ejercer el voto así como a ser elegibles para los cargos públicos. Discurría la autora que los demócratas de la sociedad americana no podían negarles esa facultad, dado que partían de la verdad evidente según la cual todos los hombres eran creados iguales y dotados de algunos derechos inalienables como la vida, la libertad y la búsqueda de la felicidad. La clave de la cuestión planteada se encontraba en con-

Quinault (1993), p. 185.

Villares y Bahamonde (2003), pp. 62-66.

Para advertir la influencia del modelo electoral británico en España se puede consultar el artículo de Sierra (2009), pp. 139-167; y para conocer cómo estaba conformado en España el sistema político representativo se aconseja consultar el artículo de Romero y Caballero (2006), pp. 7-26. 
siderar como hombres a toda la raza humana, y no únicamente a la mitad de la misma. También suponía Taylor que los políticos radicales y los constitucionalistas británicos serían favorables al sufragio universal, basándose en los cambios democratizadores que se estaban produciendo en la sociedad británica ${ }^{28}$.

Las argumentaciones de John S. Mill, en general, eran más complejas que las de Taylor y de mayor alcance en sus conclusiones, aunque comparables en sus reclamaciones básicas. En el caso del sufragio femenino, hay que considerar la diferencia temporal existente entre los dos trabajos que se están contrastando, 1851 y 1869. El ensayo de Mill mostraba un desarrollo reflexivo acorde con la transformación del conjunto social, cuyas reclamaciones no estaban muy alejadas de las exigencias de las mujeres británicas. La sujeción de las mujeres, en su versión final, se gestó en la década de los años 60 del siglo XIX, y su publicación se produjo dos años después de la reforma electoral de 1867, en la que había intervenido el propio Mill como miembro del Parlamento, solicitando personalmente el derecho al sufragio femenino en la Cámara de los Comunes, en una alocución entusiasta ${ }^{29}$, pero que fue rechazada por 196 votos en contra de sus oponentes frente a 73 votos favorables.

Mill también distinguió entre el derecho a votar y el derecho a tomar parte activa en una elección como sujetos facultados para ser elegidos y ejercer cargos de responsabilidad. En sus explicaciones, hacía extensibles las mismas condiciones y restricciones de representación y de responsabilidades para las mujeres y para los hombres. En su opinión, las mujeres necesitaban el sufragio como garantía de que sus requerimientos serían objetivamente $\operatorname{considerados}^{30}$.

\subsection{La división del trabajo y la competencia mercantil}

La división del trabajo era la piedra angular del modelo económico clásico. La tendencia de los sujetos a especializarse en determinadas actividades productivas, y no en otras, era aceptada como una característica intrínseca a la naturaleza humana. La especialización de la mano de obra hacía necesario el intercambio de las producciones, porque nadie puede ser considerado autosuficiente en las sociedades industriales. Bajo el sistema productivo del modelo clásico, es el mercado la institución fundamental que canaliza la producción de los bienes en un proceso económico en crecimiento, y los mercados se expanden al existir mayores cantidades de mercancías para intercambiar. Sobre esta cuestión decía Mill en La sujeción de las mujeres que

Taylor Mill (1851), pp. 89-94.

Kizner, Robson y Robson (1980), p. 286.

Mill (1869), pp. 203 y 204. 
no todas las personas son igualmente aptas para todas las producciones. Con el reconocimiento de la libertad de elección individual, cada cual se dedicaría a elaborar aquello para lo que estuviese más dotado, dadas las aptitudes y las preferencias de cada persona. De esta manera, las ocupaciones de los trabajadores se reajustarían mediante un proceso de competencia mercantil.

En el caso de las mujeres trabajadoras, incapacitarlas para la producción y la especialización laboral era una trasgresión de los límites de la autoridad. No podía aceptarse, como caso general, que algunas personas no sirvieran para producir. Cualquier individuo debería de ser capaz de decidir por sí mismo y sin cortapisas previas sobre dicha cuestión. El hecho de haber nacido "mujer y no varón, lo mismo que negro en vez de blanco, o pechero en vez de noble", no podía condicionar la situación de la persona a lo largo de toda su vida, excluyéndola de las ocupaciones más respetables y mejor remuneradas ${ }^{31}$.

Decía Mill que resultaba ciertamente absurdo prohibir hacer a las mujeres aquello para lo que supuestamente no eran aptas, porque la simple competencia sería suficiente garantía para expulsarlas del mercado en beneficio de los varones. Y si, por el contrario, las mujeres demostraban sus capacidades laborales, sería de nuevo la competencia la que las localizaría en los sectores para los que hubiesen demostrado estar mejor preparadas. El empeño masculino de defender la vocación natural de las mujeres exclusivamente en el matrimonio y la maternidad no demostraba más que la tesis contraria, a saber: si las mujeres tuvieran libertad de elección elegirían una forma de vida diferente.

\subsection{El acceso al mercado de trabajo profesional como factor liberador de las mujeres}

Harriet Taylor concentraba en tres cuestiones el debate con sus teóricos oponentes ${ }^{32}$. Dichas cuestiones eran las que, en su opinión, agrupaban el elenco de argumentaciones de los voceros resistentes a los derechos de las mujeres. La primera de ellas se ceñía a la incompatibilidad de una vida activa e independiente con la maternidad y las tareas del hogar; la segunda se refería a salvaguardarlas de la contaminación psicológica profesional, que las llevaría irremediablemente al endurecimiento de su carácter; y la tercera cuestión concernía a la competencia laboral: resultaba inadecuado integrarlas en la oferta de trabajo porque ello incrementaría excesivamente la concurrencia por los puestos de trabajo ${ }^{33}$.

\footnotetext{
Mill (1869), pp. 164 y 165.

Gallego (2004), pp. 17-25.

Taylor Mill (1851), p. 98.
} 
En cuanto al trabajo profesional de las mujeres, las propuestas de Taylor pueden considerarse vigentes. No aceptaba la incompatibilidad normativa de la vida personal y laboral de las mujeres casadas. Si la incompatibilidad fuese real, y así se mostraría en cada caso, dijo, se resolvería por sí misma sin necesidad de preservarlas a todas de un futuro laboral. El argumento incomprensible y gravemente injusto a rebatir era la utilización de semejante considerando para excluirlas a todas del mercado de trabajo, sin reparar en la invalidez del razonamiento cuando se aplicaba a las mujeres solteras.

Harriet Taylor acostumbraba a razonar bajo el supuesto de que las mujeres estaban en posesión de sus derechos, de manera que se vislumbraba un panorama distinto para ellas. Abierto el acceso a la educación y a una vida laboral normalizada, se habría quebrado el monopolio histórico que los hombres habían aprovechado en favor de su dominación. En ese nuevo contexto, el mundo se beneficiaría con las mejores capacidades de todos sus habitantes ${ }^{34}$. No obstante, los críticos a la ampliación del mercado de trabajo argüían un perjuicio adicional: si la oferta de trabajo aumentaba bajarían los salarios, rebajándose finalmente los ingresos familiares.

Es interesante la declaración ética-económica que desplegó para defender su posición de conciliación laboral. Supongamos, dijo, que se produjera la entrada de las mujeres en los empleos monopolizados por los hombres y aceptemos el peor escenario de todos: la suma de lo que ganarían el hombre y la mujer no superaría la cantidad que actualmente ingresa el varón. La renta familiar sería la misma que antes, respondía Taylor, pero habría emergido un importante valor añadido: la mujer habría ascendido desde una condición de sirvienta hasta la condición de socia, con lo que ambos habrían salido favorecidos en su relación.

En su opinión, la competencia era aceptada como una norma reguladora de la vida humana, y resultaba tiránico e incomprensible que se planteara de manera excluyente para la mitad de la humanidad. Añadió, además, un corolario: el aumento de la competencia ocupacional iba a permitir excluir a la mano de obra infantil del trabajo industrial, una lacra de la Inglaterra de su tiempo ${ }^{35}$.

John Stuart Mill comenzaba el apartado tercero de su ensayo planteando, de la misma manera que había hecho Taylor previamente, la cuestión del monopolio laboral "del sexo fuerte". Decía Mill que la persistencia en inhabilitarlas laboralmente implicaba su confinamiento a la vida familiar, "porque la mayor parte de los miembros del sexo masculino aún no pueden tolerar la idea de vivir con un igual". Y agregaba que la injusticia de excluir a la mitad de la humanidad de las profesiones lucrativas desde su nacimiento les impediría cualificarse en los empleos que, "por

Taylor Mill (1851), p. 96.

Taylor Mill (1851), p. 100. 
el contrario, estaban abiertos y accesibles para los más estúpidos y viles del otro sexo $^{\prime \prime 36}$.

Para Mill lo sorprendente del argumento de los detractores de los derechos laborales de las mujeres era la debilidad de la carga de la prueba que manejaban, porque no bastaba con mantener que las mujeres pudieran estar, puestos en el caso y por término medio, menos dotadas que los hombres para desarrollar tareas profesionales, sino que tendrían que ser capaces de demostrar que ninguna mujer era idónea para dichas ocupaciones ${ }^{37}$.

En este planteamiento, nuevamente Mill proponía una idea que había expuesto previamente Taylor, y se preguntaba sobre la ineficiente organización económica de las sociedades que habían decidido excluir el aprovechamiento de los servicios de la mitad del género humano. En la última parte de su ensayo, dedicado a la exposición de los beneficios derivados en las costumbres e instituciones como consecuencia de la liberación efectiva de las mujeres, introdujo el mecanismo de la competencia del mercado para reforzar su tesis. En su apreciación, acrecentar la oferta de trabajo, con el consiguiente aumento de la competencia laboral, elevaría la educación de la mujer al nivel del hombre y aumentaría el número de personas aptas para la gestión de los negocios.

El libre acceso al empleo de las mujeres permitiría duplicar la suma de facultades intelectuales potenciales de toda la humanidad. Decía Mill que donde había una persona capaz para la sociedad y para el progreso, como por ejemplo un profesor o un administrador, se daría el caso de que habría dos personas, y económicamente, resultaría una pérdida de gravísima importancia negar al mundo la mitad de todo el talento que hay en él ${ }^{38}$.

Existe una diferencia notable en las opiniones de Taylor-Mill en cuanto a la actividad laboral de las mujeres casadas. Mill no era partidario, en general, de que la mujer casada trabajara fuera de casa, consideraba que su lugar estaba en el hogar al cuidado de los hijos y gestionando las ganancias del marido. El hecho de incorporar una ocupación laboral a sus tareas vitales le estaría impidiendo cumplir con sus funciones familiares, de alta consideración para Mill, e incluso consideraba que dicha actividad añadida podría volverse en contra de las mujeres, favoreciendo que muchos hombres casados descuidaran sus obligaciones de sostenimiento familiar. La cuestión fundamental en la que coincidieron Mill y Taylor era contemplar como un derecho esencial, para la dignidad de las mujeres casadas o no, la potencial capacidad para poder elegir la opción de ganar dinero ${ }^{39}$.

\footnotetext{
Mill (1869), p. 200.

Mill (1869), p. 201.

Mill (1869), pp. 234-241.

Mill (1869), pp. 198-199.
} 


\subsection{Las implicaciones de sus reflexiones sobre el modelo económico de referencia. El marco teórico de los Principios de economía}

Los comentarios que se han desarrollado hasta este momento se han ajustado a los dos ensayos citados anteriormente y referidos a La sujeción de las mujeres (Mill) y a "La liberación de las mujeres" (Taylor). Sin embargo, las cuestiones laborales pueden hacerse más exhaustivas si se las contempla desde la perspectiva de toda la masa de los trabajadores, abriendo en este caso el panorama analítico de las reflexiones a los Principios de economía.

La organización de los Principios de economía, volumen de referencia histórica para los economistas, se estructuró en cinco libros. El libro I reunía las definiciones conceptuales de la economía política clásica, con las explicaciones de los procesos de producción. Mediante las leyes de la producción quedaban conectados los factores básicos: tierra, trabajo y capital, con la producción del tipo de mercancías que los terratenientes y patronos habrían decidido elaborar, dada la tecnología imperante de cada momento histórico. En el libro II se glosaba la distribución del producto, explicándose con ello las remuneraciones de los factores. El libro III abordaba el valor o precio de las mercancías, que profundizaba en el análisis del mercado. El libro IV trataba sobre la influencia del progreso de la sociedad en su conjunto y, finalmente, el libro $\mathrm{V}$ incluía las funciones y las decisiones del gobierno sobre la producción nacional y la administración de un país. Los Principios es un compendio sobre la organización económica desde lo más concreto a lo más amplio y, en el caso que nos ocupa, las cuestiones referidas a los trabajadores se desarrollaban en el libro IV y, dentro de éste, en el capítulo VII.

Antes de proceder a comentar las cuestiones referidas al futuro de los trabajadores, es conveniente examinar los contenidos del capítulo inmediatamente anterior. En el capítulo VI, titulado "Del estado estacionario", se exponían algunas novedades ciertamente revolucionarias para la economía política clásica. Este concepto de estado estacionario, que había sido acuñado por David Ricardo en 1817 y que servía para concebir un límite máximo de la riqueza de las sociedades en estado progresivo, mostraba el techo productivo que se alcanzaría, teóricamente, a medida que se fuera agotando el motor impulsor del crecimiento económico, determinado por la reinversión continuada de los beneficios del capitalista. Importantes economistas influyentes del siglo XIX, como lo fueron Ricardo y Karl Marx, coincidieron en contemplar esta posición con preocupación, dado que dicho límite era interpretado como un mar productivo estancado. Sin embargo, ese no era el significado que le daba John Stuart Mill al estado estacionario. Al contrario que los otros teóricos, lo consideró como una posición de riqueza nacional óptima para iniciar renovados objetivos, y no menos importantes, que iban a permitir regenerar el estándar de la vida social de los trabajadores: era el momento de ocuparse en diseñar una redistribución de rentas más equitativa. 
En el pensamiento de Mill y en el de Taylor, se encontraba el deseo de lograr una sociedad más justa en su distribución de riqueza. Este objetivo estaba vinculado a lograr una mayor felicidad del conjunto social. Si el estado estacionario era una posición de riqueza adecuada para iniciar la tarea de la redistribución de las rentas, para ellos era una posición deseable.

La cuestión revolucionaria para el ideario de la economía política clásica fue que se estaba abriendo la puerta de un nuevo capitalismo social, distinto del que habían diseñado los economistas de la vieja escuela. Confesaban Mill y Taylor en los Principios su desagrado con el ideal de vida de los que defendían que el estado normal de los seres humanos era:

“... la lucha incesante por avanzar en un mundo en el que pisotear, empujar y dar codazos eran los síntomas desagradables de una de las fases del progreso social”40.

En opinión de Mill y de Taylor, la ventaja de la riqueza de Inglaterra, frente al resto de países en el siglo XIX, era suficiente para acometer un proceso de distribución de rentas. Con esta propuesta normativa de reparto de las ganancias, se había resquebrajado el bloque compacto del modelo económico clásico, se acababan de separar las leyes de la producción de las leyes de la distribución.

\subsubsection{La clase trabajadora en los Principios de economía ${ }^{41}$}

La manera en que Mill y Taylor circunscribieron el concepto de clases trabajadoras se debió a motivos puramente operativos por el uso habitual del término entre los economistas del siglo XIX. Rechazaban el supuesto de la lucha de clases. No obstante, apostillaron al comenzar el capítulo VII, no reconocían justo ni saludable una sociedad sin clases trabajadoras, ni seres humanos exceptuados de alcanzar su parte correspondiente a los trabajos inherentes de la vida humana ${ }^{42}$.

Hicieron especial referencia a la deseable incorporación laboral de las mujeres. Observaron con optimismo el cambio de una tendencia que concebía la posibilidad del libre acceso de ambos sexos a todas las ocupaciones industriales, diluyéndose la oposición favorable a la dependencia económica de las mujeres, reflejada hasta ahora en la ley y en la costumbre. Puede leerse literalmente en este capítulo que:

Mill (1996), p. 641.

41 Para conocer el nivel de vida de los trabajadores en Inglaterra se aconseja consultar el artículo de Dyer (1998), pp. 101-107, y revisar el debate publicado sobre esta cuestión de Escudero (2002), pp. 13-60.

$42 \quad$ Mill (1996), p. 644. 
"no pasará mucho tiempo sin que se reconozca que las ideas y las instituciones que han convertido el mero accidente del sexo en la base de una desigualdad de derechos legales, y en una forzosa disparidad de funciones sociales, son el mayor obstáculo al mejoramiento moral, social e incluso intelectual" ${ }^{\prime 3}$.

En el marco teórico de sus disquisiciones se trasluce la importancia de comprender que la finalidad del progreso económico, vinculado al progreso social, era concebir unas relaciones laborales diferentes y más humanizadas, marcadas por:

"la asociación de los trabajadores con los capitalistas y, en otros casos y, quizá en todos al final, relaciones laborales derivadas exclusivamente por la asociación entre los mismos trabajadores" ${ }^{44}$.

Admitieron que la primera de las dos fórmulas de organización productiva anteriormente citadas era la más frecuente y tradicional en Inglaterra. No obstante, dijeron, ya existían algunos casos, en la práctica corriente de los negocios, en los que se remuneraba con un porcentaje de las ganancias a los trabajadores manuales, mostrándose que tenía excelentes resultados ${ }^{45}$. El avance social que se produciría mediante la creación de las cooperativas favorecería la concentración del esfuerzo productivo entre sus miembros, reforzándose la responsabilidad y la independencia de los obreros implicados, lo que incrementaría el hábito de trabajo regular y continuado. Como contraprestación a su actividad, cada miembro de la cooperativa recibiría, en justicia, la recompensa a sus cualidades laborales y a su esfuerzo personal. El avance social vendría caracterizado por la ruptura del enfrentamiento entre capitalistas y obreros, aumentando la participación inteligente de todos ellos, aunándolos en los ideales de la democracia ${ }^{46}$.

Dentro de esta misma línea argumental, John Stuart Mill fue requerido como autor de los Principios de economía política a comparecer en la Comisión Parlamentaria de 6 de junio de 1850. El tema de estudio de dicha Comisión era "El progreso de la clase media y de los trabajadores", y Mill expuso, una vez más, su reflexión sobre el futuro de los trabajadores: era deseable facilitarles la posibilidad de prosperar mediante la organización de sus propias cooperativas de producción en las que serían los patronos inversores de su capital. No obstante, la inadecuada ley de asociaciones no favorecería las oportunidades dirigidas a impulsar dichas asociaciones, y el propio Mill exhortaba a la Comisión a modificar la ley ${ }^{47}$.

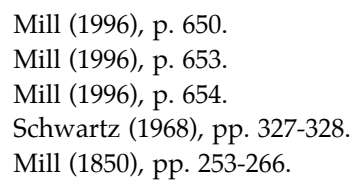


La retractación ${ }^{48}$ de Mill sobre la teoría del fondo de salarios, que suponía un acercamiento hacia los intereses de los trabajadores a la vez que admitía la eficacia de la labor sindical en la elevación de los salarios, sin perjuicio del estímulo inversor del capital, no era una cuestión aceptada generalmente por sus contemporáneos, si se exceptúan las opiniones compartidas en dicha materia por otros autores como J. R. McCulloch, R. Torrens, J. E. Cairnes ${ }^{49}$ y W. T. Thornton. Este último había sido el desencadenante de la trama, porque Mill había desarrollado sus novedosas interpretaciones comentado el libro de Thornton, titulado On Labour, y lo hizo mediante un artículo publicado en dos partes en el año 1869 en la Fortnightly Review, en donde se mostraba que la presión salarial ejercida por oferentes y demandantes a ambos lados del mercado de trabajo podía alterar el precio explicado en competencia, de manera que se rompía con ello los límites teóricos que marcaba la teoría del fondo de salarios ${ }^{50}$.

\section{Conclusiones}

En este artículo se han revisado los contenidos de tres obras: Principios de economía política y La sujeción de las mujeres de John Stuart Mill y "La liberación de las mujeres" de Harriet Taylor. La interpretación de los textos se ha realizado bajo la consideración de que existía un ideario compartido y un compromiso social explícito en los dos autores, inspirado en sus deseos de proyectar una sociedad mejorable que implicaba directamente a los colectivos de las mujeres y de los trabajadores. El marco institucional y económico en el que estaban inmersas sus reflexiones era el de la Gran Bretaña de la segunda mitad del siglo XIX, y estaba dentro de las coordenadas del modelo capitalista diseñado por los economistas clásicos, entre los que se encontraba el propio Mill. El prestigio intelectual que había adquirido John Stuart Mill a lo largo de su carrera le había dotado de capacidad para crear opinión, de manera que ambos se apoyaron en su faceta de comunicador para participar activamente en la consecución de un futuro mejorable.

La relación personal e intelectual que los había unido, y que Mill cuenta con detalle en su Autobiografía, ha permitido argumentar que hubo una colaboración efectiva en la redacción de los textos que se han comentado. No obstante, hay que puntualizar que en el caso de los Principios, únicamente se puede hablar de colabo-

\footnotetext{
$48 \quad$ Mill (1869), pp. 680-700.

49 En un apéndice referido a los Principios de Mill y colocado al final de la biografía que había escrito Bain sobre el autor, Cairnes mostraba cómo el capítulo dedicado "al futuro de la clase trabajadora" había supuesto una ruptura con la teoría desarrollada por la Escuela Clásica británica anterior a Mill, y abría la puerta hacia nuevas conjeturas doctrinarias. Cairnes en Bain (1882), p. 199. 
ración intelectual entre Mill y Taylor en algunos contenidos del Libro IV, especialmente en los capítulos VI y VII, no así en el resto de la obra.

Ambos autores fueron muy críticos con los prejuicios establecidos de su época. Este era el caso de la posición social de las mujeres, obligadas a desenvolverse en un escenario muy pequeño en el que sólo el entorno familiar era el espacio en el que podían desarrollar su personalidad, sin ninguna capacidad para decidir sobre sus vidas ni para gestionar su patrimonio. Con sus propuestas, Taylor y Mill les abrieron el camino a la verdadera educación, al trabajo profesional y al derecho a votar y a ser elegidas. Puede considerarse que la fuerza de las ideas desplegadas en las obras de Mill y de Taylor estuvo directamente relacionada con la concienciación social de la importancia que tenía, para las mujeres, y en general para todos los ciudadanos entre los que se encontraban los trabajadores británicos, el derecho al sufragio universal, no sólo como facultad directa para votar en las elecciones, sino también en cuanto al derecho a ser elegidos como representantes con capacidad de gestión y de decisión.

La comparación de los dos ensayos citados, La sujeción de las mujeres (Mill) y "La libertad de las mujeres" (Taylor), ha permitido repasar la estructura y los contenidos de las dos obras y comprobar el paralelismo de sus argumentaciones. La interpretación que se hace en este artículo es que el primero de ellos puede considerarse el origen del segundo, dada la similitud de las argumentaciones en ambos textos. El periodo que separa las dos publicaciones fue de dieciocho años y, lamentablemente, Harriet Taylor ya había muerto en 1869 cuando se publicó la obra de John Stuart Mill; probablemente, de no haber fallecido, el ensayo habría sido firmado por ambos autores. No obstante, el orden teórico y la profundidad de las explicaciones que construyó Mill eran de mayor alcance que las expuestas por Harriet Taylor, aunque sí eran coincidentes en las exigencias básicas de sus demandas, excepto en el caso de la conciliación laboral de las mujeres casadas.

El modelo capitalista clásico, basado en la división del trabajo, la propiedad privada, la iniciativa privada y el ajuste de los mercados por competencia entre los agentes implicados, era el modelo de referencia para sus disquisiciones. El argumento de la competencia en el mercado de trabajo era puesto de manifiesto por ambos autores como beneficioso para revindicar el derecho laboral de las mujeres, y en general para todos los trabajadores.

$\mathrm{Su}$ interpretación sobre el futuro de los trabajadores vislumbraba unas nuevas relaciones de producción entre capitalistas y obreros, con menor conflictividad de intereses de clase y compatible con el desarrollo cooperativo de los trabajadores. Señalaron la importancia que estaba tomando la concienciación de los intereses laborales por parte de los trabajadores, y destacaron la virtud de la educación y de la instrucción de los obreros, que favorecía la aproximación de los intereses productivos en general. 
Concibieron la conveniencia de mejorar la distribución de las rentas de los agentes de la producción, basándose en una novedosa concepción económica que proponía la separación de las leyes de la producción y de las leyes de la distribución. En el respeto a las leyes de la producción, que eran objetivas y por tanto intocables, consideraron diferente el caso de las leyes de la distribución de las rentas, que estaban influidas por las costumbres y eran dependientes de la voluntad de los individuos, por lo que eran susceptibles de ser modificadas y mejorables. Con esta propuesta se abrió la puerta a un capitalismo social influido por un pensamiento socialista moderado.

John Stuart Mill fue un intelectual comprometido con la consecución de una sociedad más abierta, conformada por ciudadanos libres y con igualdad de derechos civiles y políticos, sin distinciones por razón de raza o de sexo. Su relación intelectual con Harriet Taylor estuvo firmemente asentada en el deseo de remover los prejuicios sociales, políticos y económicos sobre los que se detenían sus escritos. Las tres obras analizadas: Principios de economía política, La Sujeción de las mujeres y "La liberación de las mujeres", están impregnados de pensamientos compartidos por ambos autores, cuyas ideas se han distribuido en este artículo en cinco planos: el freno de la tradición y de la costumbre en el progreso social, la educación como elemento básico para evolución personal, el derecho a ejercer el sufragio y a ser elegido, el acceso al mercado de trabajo y el futuro progreso de los trabajadores.

\section{Bibliografía}

ANNAS, Julia (1998): "Mill and Subjection of Woman”, en Smith, G.W., John Stuart Mill's Social and Political Thoght, Routledge, Londres, pp. 231-245.

AUGUST, Eugene (1975): John Stuart Mill: A mind at Large, Charles Scribner's Sons, Londres.

BAIN, Alexander (1882): John Stuart Mill: A Criticism with personal recollections, Longmans, Green and Co., Londres.

COURTNEY, W. L. (1888): Life of John Stuart Mill, Walter Scott Ltd, Londres.

CAIRNES, John Elliot (1967 [1874]): Some Leading Principles of Political Economy Newly Expounded, A. M. Kelly, Nueva York.

DYER, Christopher (1998): "La historia de los niveles de vida de Inglaterra, 12001800: Problemas y enfoques", Historia Agraria, n. ${ }^{\circ}$ 16, pp. 101-117.

ESCUDERO, Antonio (2002): "Volviendo a un viejo debate: el nivel de vida de la clase obrera británica durante la Revolución Industrial", Historia Industrial, n. ${ }^{\circ} 21$, pp. 13-60.

FORGET, Evelyn L. (2003): “John Stuart Mill, Harriet Taylor and French Social Theory “, en DIMAND, R. y NYLAND, C. (ed.), The Status of Women in Classical Economic Thought, Edward Elgar, Cheltenham, UK y Northampton, MA, USA. 
GALLEGO ABAROA, Elena (2005): Mujeres economistas 1816-1898, Delta, Madrid.

GILL, Emily R. (1991): "Mill and Sexual Equality", The American Political Science Review, vol. 85, n. ${ }^{\circ}$ 2, marzo, pp. 276-278.

HAYEK, Friedrich A. (1951): John Stuart Mill and Harriet Taylor. Their friendship and subsequent marriage, Routledge, Londres.

KIZNER, L. Bruce; ROBSON, Ann P. y ROBSON, John M. (1992): A Moralist in and out of Parliament: John Stuart Mill at Westminster, Toronto University Press, Toronto.

JACOBS, Jo Ellen (1994): “The Lot of Gifted Ladies is Hard: A Sutudy of Harriet Taylor Mill Criticism”, Hypatia, vol. 9, n. ${ }^{\circ}$, pp. 133-162.

JACOBS, Jo Ellen y HARMS PAYNE, Paula (1998): The Complete Works of Harriet Taylor, Indiana University Press, Bloomington.

MILL, John Stuart (1951 [1831]): "El matrimonio y el divorcio", en HAYEK, F. A., John Stuart Mill and Harriet Taylor. The friendship and subsequent marriage, Routledge, Londres.

-(2006 [1850]): "Parlamentary Papers, 1850, XIX", en Collected Works of John Stuart Mill, Essays on Economics and Society 1850-1879, University of Toronto Press, Toronto.

-(1869): “On Labour, its Wrongful Claims and Rightful Dues, its Actual Present and Possible Future", Fortnightly Review, mayo, pp. 505-518 y junio, pp. 680700 .

—(2000 [1869]): “El sometimiento de las mujeres”, en MILL, John Stuart y TAYLOR, Harriet, Ensayos sobre la igualdad de los sexos, con un prólogo de Victoria Camps y un apéndice de Emilia Pardo Bazán, Madrid, Mínimo Tránsito.

-(1986 [1873]): Autobiografía, Alianza, Madrid.

-(1984): en ROBSON, John M. (ed.), Essays on Equality, Law, and Education, University of Toronto Press, Routledge y Kegan Paul, Toronto y Londres.

—(1996 [1873]): Principios de economía política, edición de 1873, Fondo de Cultura Económica, México.

-(2006): en ROBSON, John M. y STILLINGER, Jack (eds.), Autobiography and Literary Essays, Collected Works of John Stuart Mill, Toronto University Press, Toronto.

MILL, John Stuart y TAYLOR MILL, Harriet (2001): Ensayos sobre la igualdad sexual, con una introducción de Neus Campillo, Cátedra, Instituto de la Mujer, Madrid.

MINEKA, Francis E. y LINDLEY, Dwight N. (1973) (ed.): The Later Letters of John Stuart Mill, Collected Works of John Stuart Mill, XIV-XVII, University of Toronto Press, Toronto.

MORLEY, John (1873): "The Death of Mr. Mill, Morley", Fortnightly Review, n.s. XIII, junio, p. 670. 
HAYEK, Friedrich A. (1951): John Stuart Mill and Harriet Taylor. Their friendship and subsequent marriage, Routledge, Londres.

GALLEGO ABAROA, Elena (2007): "La liberación de las mujeres y la economía según Harriet Taylor Mill (1807-1858)", en PERDICES DE BLAS, Luis y GALLEGO ABAROA, Elena, Mujeres economistas, Ecobook, Madrid, pp. 55-81.

PUJOL, Michèle (1996): "The feminist economic thought of Harriet Taylor (180758)", en DIMAND, Robert; DIMAND, Mary A.; FORGET, Evelyn L., Women of Value, Feminist Essays on the History of Women Economics, Edward Elgar, Aldershot, UK y Brookfield, US, pp. 82-102.

PACKE, Michael, S. J. (1954): The Life of John Stuart Mill, Secker and Warburg, Londres.

PUGH, Evelyn L. (1978): “John Stuart Mill, Harriet Taylor, and Women's Rights in America, 1850-1873”, Canadian Journal of History, vol. 13, pp. 423-442.

QUINAULT, Roland (1993): “The Industrial Revolution and Parliamentary Reform”, en O'Brien, Patrick y Quinault, Roland, The Industrial Revolution and British Society, Londres, pp. 183-202.

ROBSON, Ann P. y ROBSON, John M. (1986): “Introducción en Mill, John Stuart, 1806-1873", Newspapers Writings, Toronto University Press, Toronto.

-(1994): "Introducción en Mill, John Stuart, 1806-1873", en Sexual Equality: Writings by John Stuart Mill, Harriet Taylor Mill, and Helen Taylor, Toronto University Press, Toronto.

RODRIGUEZ BRAUN, Carlos (2006): Grandes economistas, Pirámide, Madrid.

ROMERO, Carmelo y CABALLERO, Margarita (2006): “Oligarquía y caciquismo durante el reinado de Isabel II (1833-1868), Historia Agraria, n. ${ }^{\circ} 38$, abril, pp. 7-26.

ROSE, PHYLLIS (1983): “A Marriage of Equals?”, The Nation, agosto, pp. 6-13.

-(1984): Parallel lives: Five Victorian marriages, Vintage, Nueva York.

ROSSI, Alice S. (1970) (ed.): "Introduction", en MILL, John Stuart and TAYLOR MILL, Harriet, Essays on Sex Equality, University Chicago Press, Chicago. Hay traducción al castellano en John Stuart Mill y Harriet Taylor, Ensayos sobre la igualdad de los sexos, con un prólogo de Victoria Camps y un apéndice de Emilia Pardo Bazán (2000), Mínimo Tránsito, Madrid.

ROURKE, Kevin C. (2001): John Stuart Mill and Freedom of Expression, Routledge, Londres.

SIERRA, María (2009): “El espejo inglés de la modernidad española: el modelo electoral británico y su influencia en el concepto de representación liberal", Historia y Política, n. ${ }^{\circ}$ 21, enero, pp. 139-167.

SCHWARTZ GIRÓN, Pedro (1968): La "nueva economía política" de John Stuart Mill, Tecnos, Madrid.

TAYLOR, Harriet (2005 [1851]): “La liberación de las mujeres", en GALLEGO ABAROA, Elena, Mujeres economistas 1816-1898, Delta, Madrid, pp. 17-25. 
TAYLOR, Harriet (1951 [1831]): “El matrimonio y el divorcio", en HAYEK, Friedrich A., John Stuart Mill and Harriet Taylor. Their friendship and subsequent marriage, Routledge, Londres. Hay traducción al castellano en John Stuart Mill y Harriet Taylor, Ensayos sobre la igualdad de los sexos, con un prólogo de Victoria Camps y un apéndice de Emilia Pardo Bazán (2000), Mínimo Tránsito, Madrid, y en John Stuart Mill y Harriet Taylor Mill (2001), Ensayos sobre la igualdad sexual, con una introducción de Neus Campillo, Cátedra, Instituto de la Mujer, Madrid.

—(1951 [1832]): “Un ensayo temprano”, en HAYEK, Friedich A., John Stuart Mill and Harriet Taylor. Their friendship and subsequent marriage, Routledge, Londres, pp. 275-279.

THORNTON, William Thomas (1971[1869]): On Labour, its Wrongful Claims and Rightful Dues, its Actual Present and Possible Future, McMillan and Co, Dublin. TULLOCH, Gail (1989): Mill and Sexual Equality, CO: Lynne Rienner, Boulder.

VILLARES, Ramón y BAHAMONDE, Ángel (2003): El mundo contemporáneo, Siglos XIX y XX, Taurus, Madrid. 